\title{
Exercise training in heart failure
}

\author{
Mark Abela
}

\section{Correspondence to}

Dr Mark Abela, Department of

Cardiology, Mater Dei Hospital, Msida MSD2090, Malta; markabela88@gmail.com

Received 2 February 2018 Revised 4 April 2018 Accepted 15 April 2018 Published Online First 4 May 2018
Check for updates

To cite: Abela M.

Postgrad Med J

2018:94:392-397

\section{ABSTRACT}

Exercise training (ET) in heart failure (HF) has long been established as an important part of HF care. ET is known to improve quality of life and functional capacity in a number of ways. Despite its proposed benefits, evidence supporting its routine inclusion in standard rehabilitation programme is at times conflicting, partly because of the significant heterogeneity present in available randomised controlled trials. There is lack of evidence with regard to the duration of the overall benefit, the optimal exercise regimen and whether certain types of $\mathrm{HF}$ aetiologies benefit more than others. The aim of this review is to provide an update to date literature review of the positive and negative evidence surrounding $\mathrm{ET}$ in $\mathrm{HF}$, while proposing an efficient novel in-hospital exercisebased rehabilitation programme for patients with $\mathrm{HF}$ in addition to a pre-existing HF clinic.

\section{INTRODUCTION Background}

Heart failure (HF) is a frequently distressing condition, affecting $1 \%-2 \%$ of the adult population in developed countries. ${ }^{1-4}$ Better management of patients with HF has led to higher costs, putting pressure on healthcare providers to support patient care. The poor quality of life (QOL) as a result of high symptom burden, ${ }^{56}$ along with a vast range of interplaying factors has opened the door for a more comprehensive approach which helps to facilitate health behaviour modification and self-management by lifestyle risk factor management. ${ }^{7}$ Structured and physician supervised multidisciplinary cardiac rehabilitation (CR) programmes have been shown to improve symptoms and functional capacity, together with an overall reduction in HF-specific and overall hospitalisation rates. ${ }^{8}$

\section{Concepts of CR}

Back in the 1950s, bed rest and eventually armchair treatment were widespread cardiology practice in patients presenting with heart disease. Early mobilisation in the 1970s transformed cardiology, as healthcare providers realised that cardiac and skeletal muscle deconditioning compromised patients' rehabilitation. Risk stratification of patients presenting with acute coronary syndrome in the 1980s allowed physicians to better advise gradual resumption of daily activities. The latter's importance eventually paved the way for CR programmes.

At present, rehabilitation programmes are delivered in hospital-based outpatient clinics or in community centres, depending on the healthcare system, usually starting 2-4 weeks after a cardiac event or 4-6 weeks after cardiac surgery. Delivered by specialised CR nurses, physiotherapists and exercise therapists, such a service is only possibly through an integrated multidisciplinary team, led by an experienced CR clinician. ${ }^{9}$

Following clinical assessment, six core components (box 1) help define how and what material should be included in a holistic CR programme, as per the latest British Association for Cardiovascular Prevention and Rehabilitation standard recommendations. ${ }^{10}$ Such measures help ensure the delivery of high-quality content. Patients are required to attend a number of group-based sessions, often two to three times a week for 4-6 weeks. This would consist of medical evaluation, prescribed exercise, cardiac risk factor modification, education and counselling (box 2). ${ }^{11}$ Early identification and treatment of coexisting diseases such as obstructive sleep apnoea, peripheral artery disease and psychiatric disorders have also been shown to improve QOL in this high-risk population ${ }^{12-14}$ which is why screening for these conditions is also incorporated in some programmes. Empowering patients and ensuring optimal medical therapy will increase the likelihood of patients adhering to advice and lifestyle modifications.

\section{Exercise training: the weak link}

Comprehensive exercise-based CR programmes lead to significant improvements in a number of clinically relevant end points. ${ }^{14-16} \mathrm{HF}$ clinics around the world have had a pivotal role in ensuring that the core components of $\mathrm{CR}$ in HF are met. ${ }^{17}$ In this regard, a lot of emphasis is put on managing the traditional CV risk factors. Despite years of evidence backing early physical conditioning in $\mathrm{HF},{ }^{18} \mathrm{HF}$ clinics around the world still poorly implement exercise training (ET) in daily clinical practice..$^{19}$ Less than $20 \%$ of patients with HF were participating in a CR programme,${ }^{20}$ with analysis of another cohort revealing that only $42 \%$ of those attending an HF management programme had an exercise component. $^{21}$

\section{Evidence supporting ET in HF}

The benefits of exercise have long been established in a number of small studies. Back in the days when medical treatment for HF was rather limited, Sullivan et al in $1988^{18}$ had already demonstrated the benefits of exercise in these patients. Various reports have constantly shown improvements in functional capacity and QOL, persisting even beyond 12 months. 223

The 'Heart Failure-A Controlled Trial Investigating Outcomes of Exercise Training' (HF-ACTION) study is the landmark multicentre randomised controlled trial (RCT) of ET in HF, consisting of 2331 patients, followed up for a median of 30 months. The primary analysis did not 
Box 1 Six core components of cardiac rehabilitation (adopted from BACPR Guidelines ${ }^{10}$ )

1. Health behaviour change and education.

2. Lifestyle risk factor management.

3. Medical risk management.

4. Psychosocial health.

5. Long-term strategies.

6. Audit and evaluation.

BACPR, British Association for Cardiovascular Prevention and Rehabilitation.

reveal any survival benefit for those attending ET programmes which could be partially explained by the young age of the cohort, lack of titration of the ET programme and poor compliance to their regimen. After adjusting for highly prognostic predictors of the primary endpoint, ET was associated with an $11 \%$ reduction (significant) in all-cause mortality/hospitalisation, together with a $15 \%$ reduction (significant) in cardiovascular mortality or HF hospitalisation. ${ }^{24}{ }^{25}$ Improved cardiorespiratory fitness (CRF) as illustrated by significant improvements in $\mathrm{VO}_{2 \max }$, exercise duration on cardiopulmonary exercise testing and 6 min walking distance at 3 and 12 months were all demonstrated. ${ }^{26}$ All these factors played an important role in a modest improvement in QOL. ${ }^{25} 27$ Similar to a number of smaller RCTs ${ }^{28}$ HF-ACTION trial again confirmed that adverse events were not excessively higher in the ET group, removing any doubts that ET in HF does not only confer benefit, but is also safe. ${ }^{26}$

A Cochrane review of exercise-based rehabilitation for HF (predominantly HF with reduced ejection fraction and New York Heart Association 2-3) in 4740 people (33 trials) again reaffirmed that ET reduced the rate of overall and HF-specific hospitalisation, together with an improvement in QOL, independent of the patient's age or degree of left ventricular (LV) dysfunction. These benefits were however only apparent after adjustment for highly prognostic predictors, independent of the mean dose of ET or length of follow-up. There was no survival advantage when comparing ET-based versus non-ET-based programmes. Two studies even reported that ET-based programmes could be potentially cost-effective, thanks to the quality of adjusted life years and life-years saved. ${ }^{8}$

There is however limited data regarding the benefits of ET in the long term. ${ }^{8}$ One study did however report a sustained improvement in functional capacity $\left(>60 \%\right.$ of $\left.\mathrm{VO}_{2 \mathrm{Max}}\right)$ and

Box 2 Secondary prevention programmes (adopted from Balady et al $^{11}$ )

Patient clinical evaluation.

- Nutritional counselling.

- Weight management.

- Blood pressure control.

- Diabetes management.

- Lipid management.

- Smoking cessation clinic.

- Exercise training.

- Psychosocial evaluation.

- Physical activity counselling.

- Screening programmes (obstructive sleep apnoea, peripheral artery disease, sexual dysfunction).
QOL, persisting up to 10 years, provided that supervised ET is performed regularly. These results together with the reported reduction in major cardiovascular events (HF-related hospitalisation and cardiac mortality) are encouraging. ${ }^{29}$

\section{What about $\mathrm{HF}$ with preserved ejection fraction?}

HF with preserved ejection fraction (HFPEF) is a fast growing form of HF, contributing towards $90 \%$ of newly diagnosed HF cases. ${ }^{30}$ No medications have as yet been shown to positively influence primary endpoints, with only ET at present seemingly offering some hope, based on early datasets. ${ }^{24}{ }^{31}$ ET in HFPEF may help improve intrinsic oxygen utilisation in skeletal muscles ${ }^{25}$ and augmented diastolic filling properties. ${ }^{32}$ With only eight highly heterogeneous RCTs (278 patients) currently reported, ${ }^{33-40}$ it is difficult to make any solid conclusions. ${ }^{31}$ One can however conclude that ET can be implemented safely in these patients, with some improvement in functional capacity and QOL to be expected. There is limited data on exercise-induced reversed cardiac remodelling and biomarkers. Knowledge about major clinical outcomes like hospitalisation and mortality is as yet unknown. ${ }^{31}$ As HFPEF is often associated with many comorbid conditions which are anyway likely to benefit from ET, it would be reasonable to say that as things stand, there is no evidence which precludes physicians from encouraging this therapy to such patients. ${ }^{24}$

\section{Non-ischaemic HF: the wild card}

The risk of sudden cardiac death in patients with non-ischaemic HF has hindered any developments with respect to ET. A number of small RCTs do claim ET offers significant benefit in non-ischaemic dilated cardiomyopathy. Improved exercise capacity, ${ }^{41} \mathrm{LV}$ remodelling, ${ }^{41} \mathrm{VO}_{2 \text { Peak }},{ }^{42}{ }^{43}$ diastolic parameters $^{42}{ }^{43}$ and endothelial function ${ }^{44}$ have all been reported. Two small studies reported improved functional class ${ }^{44}$ and exercise capacity $\left(\mathrm{VO}_{2 \mathrm{Mean}}\right)^{45}$ in patients with hypertrophic cardiomyopathy. Data from the ExTraMATCH meta-analysis did not show any evidence supporting ET in patients with non-ischaemic HF. ${ }^{46}$ In conclusion, there is as yet not enough evidence to support structured ET in these patients.

\section{Selecting the optimal training protocol}

There is no one universal protocol for ET in HF. An individualised approach should be pursued, after careful clinical and risk evaluation, taking into account a patient's lifestyle, personal goals and preferences. ${ }^{18}$ The frequency, intensity, type and time principle (table 1) is used to help guide exercise prescription, delivered in a hospital or home-based setting in a supervised or unsupervised manner.

Various parameters from a symptom-limited cardiopulmonary exercise test are used to help set target goals to achieve better CRF in a safe manner. $\mathrm{VO}_{2 \mathrm{Max}}$ is one such variable, a very strong predictor of disease prognosis in HF, decreasing the risk of death by $15 \%$ with an increase of $1.0 \mathrm{~mL} / \mathrm{kg}^{-1} \mathrm{~min}^{-1} \cdot{ }^{47}$ Improved

\begin{tabular}{ll}
\hline Table 1 FITT principle & \\
\hline Characteristic & Options \\
\hline Frequency & Times a week \\
Intensity & Mild vs moderate vs high \\
Type & Endurance vs resistance/strength \\
Time & Continuous vs intermittent/interval \\
\hline
\end{tabular}

FITT, frequency, intensity, type and time. 
achieved metabolic equivalents (METS) also offers prognostic benefit, with an increase of one MET achieved during a 12-week rehabilitation programme associated with a $13 \%$ reduction in overall mortality ${ }^{48} \mathrm{VO}_{2 \mathrm{Max}}$ and METS are the two main parameters, used in prescribing training intensity during endurance exercise, with the heart rate recovery and Borg Rating of Perceived Exertion scale other good objective alternatives. ${ }^{13}$ Less vigorous activities should be formulated for more deconditioned patients.

Moderate continuous intensity ET is the mainstay form of ET in HF. Its efficacy and safety are well demonstrated, highly recommended in guidelines. ${ }^{18}$ With the advent of high-intensity interval training (HIIT) emerging over the past couple of years, studies show it is also effective, ${ }^{49}$ well tolerated and safe for most patients with HF, improving functional capacity and QOL. ${ }^{22}$ One single-centre study actually reported HIIT to be superior to moderate continuous intensity training (MCT) in enhancing $\mathrm{VO}_{2 \mathrm{Max}}$ by reversing $\mathrm{LV}$ remodelling, improving cardiac output and endothelial function, ${ }^{50}$ with similar results reproduced separately. ${ }^{51}$ These conclusions have however been rebuffed ever since results were not reproduced in a larger multicentre trial, the SMARTEX-HF trial, which did not show superiority of HIIT over MCT. ${ }^{52}$

Resistance training adds muscle bulk to peripheral muscles and also increases bone mass. Augmenting blood flow to skeletal muscles decreases peripheral resistance and improves cardiac output. Despite its proposed benefits, it should complement and not substitute endurance exercise. ${ }^{18}$ Respiratory training is another avenue which is as yet poorly explored. Exercise capacity and QOL improve when inspiratory muscle training is performed in those presenting with weakness of these muscles ${ }^{53}$ which is why screening and specific training exercises should be considered in addition to endurance training. ${ }^{18}$

\section{EXERCISE CAPACITY IN HF AND UNDERLING PHYSIOLOGICAL MECHANISMS}

\section{Pathways contributing towards impaired exercise capacity}

A reduction in stroke volume coupled with lower heart rate reserve results in a number of changes in various body systems to try and compensate for poor cardiac output. ${ }^{454}$

\section{Central circulatory response}

During exercise, this is often manifested with shorter ventricular filling in response to physiological tachycardia. The ineffective increase in stroke volume in patients with systolic dysfunction and the inability to increase chamber distensibility in patients with diastolic dysfunction are the two main mechanisms contributing towards diminished exercise capacity in patients with $\mathrm{HF}^{54}$ with the absence of other markers ruling out any pulmonary limitations. ${ }^{55-57}$

\section{Peripheral response}

In an attempt to maintain adequate cardiac output, peripheral hypoperfusion encourages skeletal muscle dysfunction and atrophy, consequently decreasing peripheral resistance. By diverting blood away from peripheral muscle groups, diverting blood towards the inspiratory muscles helps improve cardiac output efficiency, ${ }^{58}$ a physiological response known as the metaboreflex. Augmented peripheral anaerobic metabolism during exercise promotes the release of lactic acid, ${ }^{54}$ reduced enzymes for oxidative metabolism, ${ }^{59}$ reductions in microvascular density $^{60}$ and decreased thigh cross-sectional area,${ }^{61}$ all of which correspond to a lower $\mathrm{VO}_{2 \mathrm{Max}}$ and total exercise time. ${ }^{54}$
Endothelial dysfunction and activation of the sympathetic and renin-angiotensin aldosterone systems

These all play a role in modulating vascular tone in patients with $\mathrm{HF}^{54}$ By upsetting the balance between nitric oxide, mechanotransducer stimulation and reactive oxygen species production, ${ }^{62}{ }^{63}$ vasoconstriction contributes towards ischaemic conditioning of skeletal muscles. These changes together with exercise-induced catecholamine release ${ }^{64}$ favour anaerobic glycolysis, thereby promoting symptoms of exercise intolerance.

\section{Physiological impact of ET}

Improvements in clinically relevant primary endpoints and QOL as a result of ET are brought about by a number of adaptations which take place in a number of different systems.

\section{Central adaptations}

Training-induced reverse remodelling ${ }^{18} 6566$ with improved $\mathrm{CRF}^{67}$ and NT-pro Brain Natriuretic Peptide (NT-proBNP) reductions have all been reported with ET. ${ }^{68}$ The Exercise training in Diastolic Heart Failure pilot study ${ }^{33}$ has also provided some insight into improved diastolic function in patients with HFPEF following ET, with further data expected in the follow-up study. ${ }^{69}$

\section{Peripheral adaptations}

Vasomotor dysregulation in peripheral muscles is also reversed at the cellular level with ET. ${ }^{540-72}$ A correlation between $\mathrm{VO}_{2 \mathrm{Max}}$ and augmented peripheral blood flow provides strong evidence which suggests that peripheral adaptations improve $\mathrm{CRF}^{73}$

\section{Neurohormonal adaptations}

Acetylcholine-mediated vasodilation and upregulation of antioxidative radical scavenger enzymes contributes towards improved peripheral vasomotor tone. ${ }^{73-75}$ ET also encourages lower sympathetic nerve activity, thereby improved vagal tone and decreased sympathetic tone. ${ }^{76-79}$ These have been shown to decrease heart rate variability, leg vascular resistance, diastolic pressure and ventilation. ${ }^{79}$

\section{Altered inflammatory status}

Reduced inflammatory cytokine levels which correlate with improvements in $\mathrm{VO}_{2 \mathrm{Max}}$ have been reported, ${ }^{80}$ suggesting that skeletal muscle myopathy in $\mathrm{HF}$ is partly inflammatory in aetiology. ${ }^{54}$

\section{Barriers to clinical application: What's holding us back?}

It has been a long and arduous struggle, taking 20 years for ET in stable HF to finally being accepted as a class 1 recommendation in international guidelines. ${ }^{81}{ }^{82} \mathrm{~A}$ number of healthcare or patient-related barriers hinder the implementation of ET in all HF clinics around the world. ${ }^{192}$ It is well known that failing to advise patients regarding the importance of non-pharmacological treatment like exercise is a predictor of poor outcome in HF which is why practical interventions should be sought to help bridge the gap. ${ }^{83}$

Lack of knowledge about the evidence supporting current recommendations, together with the limited availability of ET sites, insufficient financial investment and organisation-related factors are all valid healthcare system obstacles. ${ }^{19}$ The physiology and benefit of exercise in general are not well addressed during medical and postgraduate training which is why courses and up-to-date lectures should be incorporated regularly. 
Patient adherence on the other hand is determined by the interaction of five different aspects, including social and economic factors, patient's condition, therapy, patient perception and factors related to the healthcare setting. ${ }^{19}$ Demographic variables like age (younger than 65 years) and ethnicity (non-white patients) were significantly associated with worse adherence to CR in one meta-analysis. ${ }^{84}$ Adherence to ET was specifically shown to be rather poor $(<50 \%)$ in older patients, females and those with psychiatric issues. Lack of motivation, financial/ medical concerns and lower socioeconomic class were all shown to be strong predictors of poor adherence in one study. ${ }^{85}$ Poor social support and barriers to exercise were associated with lower exercise time in the HF-ACTION trial. ${ }^{1086}$ This same trial

\section{Main messages}

- Evidence supporting exercise training in heart failure is now well established, with small studies also showing positive benefits for heart failure with preserved ejection fraction and non-ischaemic cardiomyopathy.

- Exercise training alters multiple physiological mechanisms which help improve cardiac output and functional capacity, thereby reduce symptoms, improve quality of life and also help decrease hospitalisation.

- Despite the benefits of exercise training in heart failure dating back to the 70 s, a number of factors are still hindering its widespread implementation in heart failure rehabilitation programmes.

\section{Current research questions}

- What is the current evidence supporting the widespread implementation of exercise training in patients with heart failure?

- Why does exercise training improve functional capacity in patients with heart failure?

- What is the status on exercise training prescription in heart failure with preserved ejection fraction and non-ischaemic heart failure?

\section{Key references}

1. Cooper LB, Mentz RJ, Sun JL et al. Psychosocial factors, exercise adherence, and outcomes in heart failure patients insights from heart failure: a controlled trial investigating outcomes of exercise training (HF-ACTION). Circ Heart Fail 2015;8:1044-51.

2. Taylor RS, Sagar VA, Davies EJ, et al. Exercise-based rehabilitation for heart failure. Cochrane Database Syst Rev 2014:4:CD003331.

3. Papathanasiou G, Tsamis N, Georgiadou P, et al. Beneficial effects of physical training and methodology of exercise prescription in patients with heart failure. Hellenic J Cardiol 2008; 49:267-77.

4. Downing $J$ and Balady GJ. The role of exercise training in heart failure. JACC 2011; 58: 561-9.

5. Piepoli MF, Davos C, Francis DP, et al. Exercise training meta-analysis of trials in patients with chronic heart failure (ExTraMATCH). BMJ 2004;24;328:189.
Self assessment questions

- Most heart failure cardiac rehabilitation programmes have an exercise component.

- The risks for patients with heart failure attending exercise training sessions are higher compared with those who do not

- Exercise training in heart failure with preserved ejection fraction may confer benefit, but is as yet not recommended.

- Moderate continuous-intensity training is currently the gold standard regimen for exercise training in patients with heart failure.

- Improving functional capacity $\left(\mathrm{VO}_{2 \mathrm{Max}}\right)$ by $0.5 \mathrm{~mL} / \mathrm{kg}^{-1} \mathrm{~min}^{-1}$ decreases the risk of death by $25 \%$.

also reported that lack of enthusiasm and patient symptoms were the main reasons for poor adherence with prescribed ET, with only $29 \%-42 \%$ managing to comply with prescribed regimens 3 months after completing the CR programme. ${ }^{26}$

\section{CONCLUSIONS}

One can confidently conclude that ET in HF is safe, with the added possibility that it may reduce mortality and HF-related hospitalisation. The extensive study heterogeneity, along with the small sample sizes used for most RCTs makes it very difficult to arrive at solid conclusions. Larger studies are needed to assess the efficacy of ET in HF, while also looking at novel ways to improve adherence in exercise programmes.

Contributors MA is the sole author and has thus contributed fully to the production of this article.

Funding The author has not declared a specific grant for this research from any funding agency in the public, commercial or not-for-profit sectors.

Competing interests None declared.

Patient consent Not required.

Provenance and peer review Not commissioned; externally peer reviewed.

(c) Article author(s) (or their employer(s) unless otherwise stated in the text of the article) 2018. All rights reserved. No commercial use is permitted unless otherwise expressly granted.

\section{REFERENCES}

1 Mosterd A, Hoes AW. Clinical epidemiology of heart failure. Heart 2007;93:1137-46.

2 Redfield MM, Jacobsen SJ, Burnett JC, et al. Burden of systolic and diastolic ventricular dysfunction in the community: appreciating the scope of the heart failure epidemic. JAMA 2003:289:194-202.

3 Bleumink GS, Knetsch AM, Sturkenboom MC, et al. Quantifying the heart failure epidemic: prevalence, incidence rate, lifetime risk and prognosis of heart failure The Rotterdam Study. Eur Heart J 2004;25:1614-9.

4 Ceia F, Fonseca C, Mota T, et al. Prevalence of chronic heart failure in Southwestern Europe: the EPICA study. Eur J Heart Fail 2002;4:531-9.

5 Fukuta H, Goto T, Wakami K, et al. Effects of drug and exercise intervention on functional capacity and quality of life in heart failure with preserved ejection. European Journal of Preventive Cardiology 2016;23:78-85.

6 Taylor RS, Sagar VA, Davies EJ, et al. Exercise-based rehabilitation for heart failure. Cochrane Database Syst Rev 2014;4:CD003331.

7 Wingham J, Harding G, Britten N, et al. Heart failure patients' attitudes, beliefs, expectations and experiences of self-management strategies: a qualitative synthesis. Chronic IIIn 2014;10:135-54.

8 Ponikowski P, Voors AA, Anker SD, et al. 2016 ESC Guidelines for the diagnosis and treatment of acute and chronic heart failure: the task force for the diagnosis and treatment of acute and chronic heart failure of the European Society of Cardiology (ESC). Developed with the special contribution of the Heart Failure Association (HFA) of the ESC. Eur J Heart Fail 2016;18:891-975.

9 Dalal HM, Doherty P, Taylor RS, et al. Cardiac rehabilitation. BMJ 2015;351:h5000.

10 British Association for Cardiovascular Prevention and Rehabilitation Exercise Professionals Group. Core competences for the physical activity and exercise component. standards and core components. 3rd edn, 2017. 
11 Balady GJ, Williams MA, Ades PA, et al. Core components of cardiac rehabilitation/ secondary prevention programs: 2007 update: a scientific statement from the American Heart Association Exercise, Cardiac Rehabilitation, and Prevention Committee, the Council on Clinical Cardiology; the Councils on Cardiovascular Nursing, Epidemiology and Prevention, and Nutrition, Physical Activity, and Metabolism; and the American Association of Cardiovascular and Pulmonary Rehabilitation. J Cardiopulm Rehabil Prev 2007;27:121-9.

12 Jafari B. Rehabilitation of cardiovascular disorders and sleep apnea. Sleep Med Clin 2017;12:193-203.

13 Matthews S, Smith P, Chadwick P, et al. Implementing a community-based structured exercise programme for patients with peripheral arterial disease in conjunction with an existing cardiac rehabilitation service results in better outcomes. British Journal of Diabetes 2016;16:193-7.

14 Maines TY, Lavie CJ, Milani RV, et al. Effects of cardiac rehabilitation and exercise programs on exercise capacity, coronary risk factors, behavior, and quality of life in patients with coronary artery disease. South Med J 1997;90:43-9.

15 Taylor RS, Unal B, Critchley JA, et al. Mortality reductions in patients receiving exercise-based cardiac rehabilitation: how much can be attributed to cardiovascular risk factor improvements? Eur J Cardiovasc Prev Rehabil 2006;13:369-74.

16 Piepoli MF, Corrà U, Benzer W, et al. Secondary prevention through cardiac rehabilitation: from knowledge to implementation. A position paper from the Cardiac Rehabilitation Section of the European Association of Cardiovascular Prevention and Rehabilitation. Eur J Cardiovasc Prev Rehabil 2010;17:1-17.

17 Mampuya WM. Cardiac rehabilitation past, present and future: an overview. Cardiovasc Diagn Ther 2012;2:38-49.

18 Piepoli MF, Conraads V, Corrà U, et al. Exercise training in heart failure: from theory to practice. A consensus document of the Heart Failure Association and the European Association for Cardiovascular Prevention and Rehabilitation. Eur J Heart Fail 2011;13:347-57.

19 Bjarnason-Wehrens B, McGee H, Zwisler AD, et al. Cardiac rehabilitation in Europe: results from the European Cardiac Rehabilitation Inventory Survey. Eur J Cardiovasc Prev Rehabil 2010;17:410-8.

20 Jaarsma T, Strömberg A, De Geest S, et al. Heart failure management programmes in Europe. Eur J Cardiovasc Nurs 2006;5:197-205.

21 Zwisler AD, Soja AM, Rasmussen S, et al. Hospital-based comprehensive cardiac rehabilitation versus usual care among patients with congestive heart failure, ischemic heart disease, or high risk of ischemic heart disease: 12-month results of a randomized clinical trial. Am Heart J 2008;155:1106-13.

22 Nilsson BB, Westheim A, Risberg MA. Long-term effects of a group-based highintensity aerobic interval-training program in patients with chronic heart failure. $\mathrm{Am} \mathrm{J}$ Cardiol 2008;102:1220-4

23 Rector TS, Tschumperlin LK, Kubo SH, et al. Use of the living with heart failure questionnaire to ascertain patients' perspectives on improvement in quality of life versus risk of drug-induced death. J Card Fail 1995;1:201-6.

24 Forman DE, Sanderson BK, Josephson RA, et al. Heart failure as a newly approved diagnosis for cardiac rehabilitation: challenges and opportunities. J Am Coll Cardiol 2015;65:2652-9.

25 O'Connor CM, Whellan DJ. Understanding heart failure through the HF-ACTION baseline characteristics. Am Heart J 2009;158:S1-S5.

26 O'Connor CM, Whellan DJ, Lee KL, et al. Efficacy and safety of exercise training in patients with chronic heart failure: HF-ACTION randomized controlled trial. JAMA 2009:301:1439-50.

27 Ambrosy AP, Cerbin LP, DeVore AD, et al. Aerobic exercise training and general health status in ambulatory heart failure patients with a reduced ejection fraction-findings from the heart failure and a controlled trial investigating outcomes of exercise training (HF-ACTION)trial. Am Heart J 2017;186:130-8.

28 McKelvie RS. Exercise training in patients with heart failure: clinical outcomes, safety, and indications. Heart Fail Rev 2008;13:3-11.

29 Belardinelli R, Georgiou D, Cianci G, et al. 10-year exercise training in chronic heart failure: a randomized controlled trial. J Am Coll Cardiol 2012;60:1521-8.

30 Haykowsky MJ, Kitzman DW. Exercise physiology in heart failure and preserved ejection fraction. Heart Fail Clin 2014;10:445-52.

31 Palau P, Núñez E, Domínguez E, et al. Physical therapy in heart failure with preserved ejection fraction: A systematic review. Eur J Prev Cardiol 2016;23:4-13.

32 Zile MR, Gottdiener JS, Hetzel SJ, et al. Prevalence and significance of alterations in cardiac structure and function in patients with heart failure and a preserved ejection fraction. Circulation 2011;124:2491-501.

33 Edelmann F, Gelbrich G, Düngen HD, et al. Exercise training improves exercise capacity and diastolic function in patients with heart failure with preserved ejection fraction: results of the Ex-DHF (Exercise training in Diastolic Heart Failure) pilot study. J Am Coll Cardiol 2011;58:1780-91.

34 Gary R. Exercise self-efficacy in older women with diastolic heart failure: results of a walking program and education intervention. J Gerontol Nurs 2006;32:31-9.

35 Kitzman DW, Brubaker PH, Morgan TM, et al. Exercise training in older patients with heart failure and preserved ejection fraction: a randomized, controlled, single-blind trial. Circ Heart Fail 2010;3:659-67.

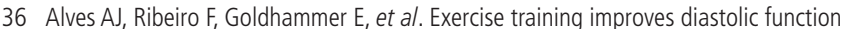
in heart failure patients. Med Sci Sports Exerc 2012;44:776-85.
37 Smart NA, Haluska B, Jeffriess L, et al. Exercise training in heart failure with preserved systolic function: a randomized controlled trial of the effects on cardiac function and functional capacity. Congest Heart Fail 2012;18:295-301.

38 Kitzman DW, Brubaker $\mathrm{PH}$, Herrington DM, et al. Effect of endurance exercise training on endothelial function and arterial stiffness in older patients with heart failure and preserved ejection fraction: a randomized, controlled, single-blind trial. J Am Coll Cardiol 2013;62:584-92.

39 Palau P, Domínguez E, Núñez E, et al. Effects of inspiratory muscle training in patients with heart failure with preserved ejection fraction. Eur J Prev Cardiol 2014;21:1465-73.

$40 \mathrm{Kim}$ C, Choi HE, Lee BJ. Cardiac rehabilitation of a patient with an advanced dilated cardiomyopathy: a case report. Ann Rehabil Med 2014;38:554-8.

41 Myers J, Wagner D, Schertler T, et al. Effects of exercise training on left ventricular volumes and function in patients with nonischemic cardiomyopathy: application of magnetic resonance myocardial tagging. Am Heart J 2002;144:719-25.

42 Belardinelli R, Georgiou D, Cianci G, et al. Exercise training improves left ventricular diastolic filling in patients with dilated cardiomyopathy. Clinical and prognostic implications. Circulation 1995;91:2775-84.

43 Legallois D, Belin A, Nesterov SV, et al. Cardiac rehabilitation improves coronary endothelial function in patients with heart failure due to dilated cardiomyopathy: $A$ positron emission tomography study. Eur J Prev Cardiol 2016;23:129-36.

44 Klempfner R, Kamerman T, Schwammenthal E, et al. Efficacy of exercise training in symptomatic patients with hypertrophic cardiomyopathy: results of a structured exercise training program in a cardiac rehabilitation center. Eur J Prev Cardiol 2015;22:13-19.

45 Saberi S, Wheeler M, Bragg-Gresham J, et al. Effect of moderate-intensity exercise training on peak oxygen consumption in patients with hypertrophic cardiomyopathy: a randomized clinical trial. JAMA 2017:317:1349-57.

46 Piepoli MF, Davos C, Francis DP, et al. Exercise training meta-analysis of trials in patients with chronic heart failure (ExTraMATCH). BMJ 2004:328:189.

47 Keteyian SJ, Brawner CA, Savage PD, et al. Peak aerobic capacity predicts prognosis in patients with coronary heart disease. Am Heart J 2008;156:292-300.

48 Martin BJ, Arena R, Haykowsky M, et al. Cardiovascular fitness and mortality after contemporary cardiac rehabilitation. Mayo Clin Proc 2013;88:455-63.

49 Spee RF, Niemeijer VM, Wijn PF, et al. Effects of high-intensity interval training on central haemodynamics and skeletal muscle oxygenation during exercise in patients with chronic heart failure. Eur J Prev Cardiol 2016:23:1943-52

50 Wisløff U, Støylen A, Loennechen JP, et al. Superior cardiovascular effect of aerobic interval training versus moderate continuous training in heart failure patients: a randomized study. Circulation 2007;115:3086-94.

51 Fu TC, Wang CH, Lin PS, et al. Aerobic interval training improves oxygen uptake efficiency by enhancing cerebral and muscular hemodynamics in patients with heart failure. Int J Cardiol 2013;167:41-50.

52 Ellingsen $\varnothing$, Halle M, Conraads V, et al. High-intensity interval training in patients with heart failure with reduced ejection fraction. Circulation 2017;135:839-49.

53 Ribeiro JP, Chiappa GR, Neder JA, et al. Respiratory muscle function and exercise intolerance in heart failure. Curr Heart Fail Rep 2009;6:95-101.

54 Papathanasiou G, Tsamis N, Georgiadou P, et al. Beneficial effects of physical training and methodology of exercise prescription in patients with heart failure. Hellenic $J$ Cardiol 2008:49:267-77.

55 Wasserman K. Dyspnea on exertion. Is it the heart or the lungs? JAMA 1982;248:2039-43.

56 Sullivan MJ, Knight B, Higginbotham MB, et al. Relation between central and peripheral hemodynamics during exercise in patients with severe heart failure. Circulation 1989:80:769-81.

57 Balady GJ, Arena R, Sietsema K, et al. clinician's guide to cardiopulmonary exercise testing in adults: a scientific statement from the American Heart Association. Circulation 2010;122:191-225.

58 Chicco AJ. Exercise training in prevention and rehabilitation: which training mode is best? Minerva Cardioangiol 2008;56:557-70.

59 Duscha BD, Annex BH, Green HJ, et al. Deconditioning fails to explain peripheral skeletal muscle alterations in men with chronic heart failure. J Am Coll Cardiol 2002;39:1170-4.

60 Duscha BD, Kraus WE, Keteyian SJ, et al. Capillary density of skeletal muscle: a contributing mechanism for exercise intolerance in class II-III chronic heart failure independent of other peripheral alterations. J Am Coll Cardiol 1999;33:1956-63.

61 Harrington D, Anker SD, Chua TP, et al. Skeletal muscle function and its relation to exercise tolerance in chronic heart failure. J Am Coll Cardiol 1997:30:1758-64.

62 Poelmann RE, Van der Heiden K, Gittenberger-de Groot A, et al. Deciphering the endothelial shear stress sensor. Circulation 2008:117:1124-6.

63 Nauli SM, Kawanabe Y, Kaminski JJ, et al. Endothelial cilia are fluid shear sensors that regulate calcium signaling and nitric oxide production through polycystin-1. Circulation 2008:117:1161-71.

64 Francis G. Neurohormonal responses to exercise in heart failure. In: Balady GJ, Pina IL, eds. Exercise and heart failure. Armonk, New York: Futura Publishing Company, 1997. 
65 Haykowsky MJ, Liang Y, Pechter D, et al. A meta-analysis of the effect of exercise training on left ventricular remodeling in heart failure patients: the benefit depends on the type of training performed. J Am Coll Cardiol 2007;49:2329-36.

66 Hambrecht R, Gielen S, Linke A, et al. Effects of exercise training on left ventricular function and peripheral resistance in patients with chronic heart failure: $\mathrm{A}$ randomized trial. JAMA 2000;283:3095-101.

67 Demopoulos L, Bijou R, Fergus I, et al. Exercise training in patients with severe congestive heart failure: enhancing peak aerobic capacity while minimizing the increase in ventricular wall stress. J Am Coll Cardiol 1997;29:597-603.

68 Giallauria F, De Lorenzo A, Pilerci F, et al. Reduction of N terminal-pro-brain (B-type) natriuretic peptide levels with exercise-based cardiac rehabilitation in patients with left ventricular dysfunction after myocardial infarction. Eur I Cardiovasc Prev Rehabil 2006;13:625-32.

69 Edelmann F, Bobenko A, Gelbrich G, et al. Exercise training in Diastolic Heart Failure (Ex-DHF): rationale and design of a multicentre, prospective, randomized, controlled, parallel group trial. Eur J Heart Fail 2017;19:1067-74.

70 Adamopoulos S, Coats AJ, Brunotte F, et al. Physical training improves skeletal muscle metabolism in patients with chronic heart failure. J Am Coll Cardiol 1993;21:1101-6.

71 Mancini DM, Coyle E, Coggan A, et al. Contribution of intrinsic skeletal muscle changes to 31P NMR skeletal muscle metabolic abnormalities in patients with chronic heart failure. Circulation 1989;80:1338-46.

72 Hambrecht R, Niebauer J, Fiehn E, et al. Physical training in patients with stable chronic heart failure: effects on cardiorespiratory fitness and ultrastructural abnormalities of leg muscles. J Am Coll Cardiol 1995;25:1239-49.

73 Hornig B, Maier V, Drexler H. Physical training improves endothelial function in patients with chronic heart failure. Circulation 1996:93:210-4

74 Hambrecht R, Fiehn E, Weigl C, et al. Regular physical exercise corrects endothelial dysfunction and improves exercise capacity in patients with chronic heart failure. Circulation 1998:98:2709-15.

75 Adams V, Linke A, Kränkel N, et al. Impact of regular physical activity on the NAD(P) $\mathrm{H}$ oxidase and angiotensin receptor system in patients with coronary artery disease. Circulation 2005;111:555-62.

76 Kiilavuori K, Toivonen L, Näveri $\mathrm{H}$, et al. Reversal of autonomic derangements by physical training in chronic heart failure assessed by heart rate variability. Eur Heart $J$ 1995;16:490-5.

77 Adamopoulos S, Ponikowski P, Cerquetani E, et al. Circadian pattern of heart rate variability in chronic heart failure patients. Effects of physical training. Eur Heart $J$ 1995;16:1380-6.
78 Roveda F, Middlekauff HR, Rondon MU, et al. The effects of exercise training on sympathetic neural activation in advanced heart failure: a randomized controlled trial. J Am Coll Cardiol 2003;42:854-60.

79 Piepoli M, Clark AL, Volterrani M, et al. Contribution of muscle afferents to the hemodynamic, autonomic, and ventilatory responses to exercise in patients with chronic heart failure: effects of physical training. Circulation 1996;93:940-52.

80 Gielen S, Adams V, Möbius-Winkler S, et al. Anti-inflammatory effects of exercise training in the skeletal muscle of patients with chronic heart failure. J Am Coll Cardiol 2003:42:861-8.

81 Milani RV, Lavie CJ, Mehra MR. Reduction in C-reactive protein through cardiac rehabilitation and exercise training. J Am Coll Cardiol 2004;43:1056-61.

82 Conraads VM, Deaton C, Piotrowicz E, et al. Adherence of heart failure patients to exercise: barriers and possible solutions: a position statement of the Study Group on Exercise Training in Heart Failure of the Heart Failure Association of the European Society of Cardiology. Eur J Heart Fail 2012;14:451-8.

83 Komajda M, Lapuerta P, Hermans $\mathrm{N}$, et al. Adherence to guidelines is a predictor of outcome in chronic heart failure: the MAHLER survey. Eur Heart J 2005;26:1653-9.

84 Turk-Adawi KI, Oldridge NB, Tarima SS, et al. Cardiac rehabilitation patient and organizational factors: what keeps patients in programs? J Am Heart Assoc 2013;2:000418.

85 Barbour KA, Miller NH. Adherence to exercise training in heart failure: a review. Heart Fail Rev 2008;13:81-9.

86 Cooper LB, Mentz RJ, Sun JL, et al. Psychosocial factors, exercise adherence, and outcomes in heart failure patients: insights from heart failure: a controlled trial investigating outcomes of exercise training (HF-ACTION). Circ Heart Fail 2015;8:1044-51.

\section{Answers}

1. False

2. False

3. True

4. True

5. False 